American Journal of Applied Sciences 7 (9): 1190-1194, 2010

ISSN 1546-9239

(C) 2010 Science Publications

\title{
Cardiotrophin-1 in Patients with Acute Myocardial Infarction
}

\author{
${ }^{1}$ Abdolreza Sotoodeh Jahromi, ${ }^{2}$ Mohammad Shojaie and ${ }^{3}$ Abdoulhossain Madani \\ ${ }^{1}$ Department of Immunology, \\ ${ }^{2}$ Department of Cardiology, \\ Jahrom University of Medical Science, Jahrom, Iran \\ ${ }^{3}$ Department of Public Health, Hormozgan University of Medical Science, \\ Bandarabbas, Iran
}

\begin{abstract}
Problem statement: Myocardial infarction is the combined result of environmental and personal factors. Prothrombotic factors might play an important role in this phenomenon. Inflammation plays a pivotal role in atherosclerosis and coronary heart disease. Cardiotrophin-1 (CT-1), a member of the IL-6 family of cytokines, was identified as a growth factor for cardiac myocytes that induces cardiomyocyte hypertrophy and stimulates cardiac fibroblasts, protects myocytes from cell death. This study was designed to investigate whether plasma concentration of Cardiotrophin-1 (CT-1), in patients who had the first acute myocardial infarction and to analyze their relationship with traditional cardiovascular risk factors. Approach: This study was carried out on 45 patients with Acute Myocardial Infarction (AMI) in their first $24 \mathrm{~h}$ of admission as case group and 36 healthy matched individuals were studied as the control. Plasma level of cardiotrophin-1 was determined by enzymelinked immunosorbent assay and the results were compared. Results: Plasma CT-1 levels in the patients with AMI on admission $615.279 \pm 5.109 \mathrm{pmol} \mathrm{L}^{-1}$ were significantly higher than those in the control group 534.767 $\pm 6.750 \mathrm{pmol} \mathrm{L}^{-1}(\mathrm{p}=0.001)$. Plasma CT-1 level was not correlated with diabetes mellitus, hyperlipidemia, sex, age and smoking. Conclusion: Our findings suggested that high plasma CT-1 level in patients with AMI is indicative of hypercoagulable state that is not related to the traditional cardiovascular risk factors.
\end{abstract}

Key words: Cardiotrophin-1, myocardial infarction, hypercoagulable

\section{INTRODUCTION}

Myocardial Infarction (MI) is the combined result of environmental factors and personal predispositions (Zimmerman et al., 1995; Ahmed, 2010; Dehlaghi et al., 2008; Jahromi et al., 2010). Factors such as low serum adiponectin (Shojaie et al., 2009) and annexin V levels (Shojaie et al., 2009), infectious diseases such as Mycoplasma pneumonia (Pourahmad et al., 2009), Periodontal Disease (Najafi-Parizi and Lori, 2005) and Opium Addiction (Azimzade-Sarwar et al., 2005) are a part of involving factors in MI. Inflammation plays a pivotal role in atherosclerosis and coronary heart disease (Trepels et al., 2004).

In line with convincing experimental records as well as abundant clinical findings the present view of atherosclerosis points to inflammation as an important regulator of atherosclerotic plaque formation and progression leading to the lethal clinical endpoints myocardial infarction, stroke or sudden cardiac death. The underlying mechanisms have been a subject of intense research during the last decades. In this view, the Interleukin-6 (IL-6) cytokines have been shown to contribute to both, atherosclerotic plaque development and plaque destabilization via a variety of mechanisms. These involve the release of other pro-inflammatory cytokines, oxidation of lipoproteins by phospholipases, stimulation of acute phase protein secretion, the release of prothrombotic mediators and the activation of matrix metalloproteinases (Schuett et al., 2009).

Cardiotrophin-1 (CT-1), a member of the IL-6 family of cytokines, was identified as a growth factor for cardiac myocytes that induces cardiomyocyte hypertrophy and stimulates cardiac fibroblasts, protects myocytes from cell death (Freed et al., 2003; 2005; Khan et al., 2006).

Previous studies have shown that the elevation of CT-1 in human hypertension (Freed et al., 2003; Lopez et al., 2005) and its potential role in post-MI wound healing (Pemberton et al., 2005).

This study was designed to investigate plasma concentration of CT-1, in patients who had the first acute myocardial infarction and to analyze their relationship with traditional cardiovascular risk factors. 


\section{MATERIALS AND METHODS}

Subjects: This case-control research recruited 45 consecutive patients with Acute Myocardial Infarction (AMI) including 31 men and 14 women with the mean age of $62.7 \pm 13.1$ years old who were taken to the emergency room of Peymanieh Hospital (Jahrom, Iran) with the chief complaint of chest pain from Feb 2007 to May 2008. We also selected 36 healthy individuals as our control group and matched them for age, sex and other CAD risk factors such as Hyper Tension N (HTN), Diabetes Mellitus (DM) and Hyper Li Pidemia (HLP).

The study protocol was accepted by research ethics committee of Jahrom University of Medical Sciences and informed consents were obtained from all participants before enrollment.

A questionnaire including information about the past medical and drug history (HTN, HLP, DM, smoking, chronic diseases such as collagen vascular diseases and asthma), family history of Coronary Artery Disease (CAD) and demographic information was completed for each patient.

The exclusion criteria were past MI history, the presence of severe liver syndrome, tumor, recent cardiac surgery, angioplasty, stable or unstable angina, receiving of anticoagulant drugs, haemolysis, abortion, history of deep vein or arterial thrombosis, inflammatory and rheumatic diseases such as collagen vascular disease, SLE and APA syndrome.

Definitions: AMI was defined as chest pain lasting more than $30 \mathrm{~min}$ with ischemic electrocardiographic changes and was confirmed by the presence of total Creatinine Phospho Kinase (CPK) or MB fraction levels of more than twice the upper normal limit (Antman et al., 2008; Cannon, 2010). The lack of any narrowing in coronary artery diameter was considered as normal coronary angiography.

Blood pressure was measured two times in sitting position after $5 \mathrm{~min}$ of rest using a mercury sphygmomanometer. Hypertension was defined as blood pressure more than $130 / 85 \mathrm{mmHg}$ or use of any antihypertensive medication (Victor and Kaplan, 2008). DM was defined by a physician's diagnosis, a fasting plasma glucose level of $\geq 126 \mathrm{mg} \mathrm{dL}^{-1}$ or use of diabetic medications (Foster and Pitts, 2009). Echocardiography was done for all patients during their hospital stay by one cardiologist. Ejection Fraction (EF) is defined to be normal ( $>55 \%)$, mild $(45-54 \%)$, moderate $(30-44 \%)$ and $(>30 \%)$ severe LV systolic dysfunction (Lang, 2009).

Laboratory analysis: Fasting levels of serum total cholesterol, High Density Lipoprotein (HDL) cholesterol, Low Density Lipoprotein cholesterol (LDL) and Triglycerides (TG) were measured in Research Laboratory of Jahrom Medical University. Total cholesterol and triglyceride levels were determined by enzymatic techniques using a Selectra E biochromatic analyzer. HDL and LDL cholesterol level was determined after glucose levels were measured by the glucose oxidase method. CPK were calculated by an enzymatic method.

Blood samples (5 cc) were obtained by venipuncture from the patients immediately after admission before starting any IV medications by skilled personnel and for lipid profile and fasting blood sugar at the first $24 \mathrm{~h}$ of AMI after $12 \mathrm{~h}$ of fasting.

In control group all blood sample were obtained after $12 \mathrm{~h}$ of fasting then separated plasma was frozen at $-70^{\circ} \mathrm{C}$ for later processing.

Plasma concentration of cardiotrophin-1 was determined by Enzyme Linked Immune Sorbent Assay (ELISA) using high-sensitivity commercial kits.

(Biovendor Company, Cat. No.: RD192026200R, CZECH REPUBLIC) according its manufacturer's recommendation.

Statistical analysis: Statistical analyses were performed by SPSS (version 15; SPSS, Inc., Chicago, IL).

Data were expressed as mean \pm 1 SD. Continuous variables with little-to-mild skewness were summarized as mean $\pm \mathrm{SD}$ and compared using Student's t-test.

Discrete variables were presented as frequencies and group percentages. Nominal variables were tested with Pearson's 2 test and Binary variables were tested with the chi square test. Pearson correlation coefficients were calculated to evaluate unadjusted (univariate) associations between CT-1 and other variables. Generalized Linear Models were used to adjust smoking between two groups. All tests were two-tailed with a 0.05 type I error rate. ANOVA and KruskalWallis test were used to evaluate association of CT-1 with different type of AMI and EF.

\section{RESULTS}

The demographic and clinical characteristics of the study groups, as well as laboratory variables are shown in Table 1. In the patient group 6 cases (14\%) had NonSt Elevation MI (NSTEMI) and 37 (86\%) had ST Elevation MI (STEMI). There was no significant difference between the two groups regarding the following variables: age, sex, HTN, DM, LDL, HDL, total cholesterol and TG. Plasma CT-1 levels in patients with AMI on admission were significantly higher than those in the control group $\left(615.279 \pm 5.109 \mathrm{pmol} \mathrm{L}^{-1} \mathrm{Vs}\right.$ $\left.534.767 \pm 6.750 \mathrm{pmol} \mathrm{L}^{-1}, \mathrm{p}=0.001\right)$. 
Am. J. Applied Sci., 7 (9): 1190-1194, 2010

Table 1: Demographic and clinical characteristics of study and control groups

\begin{tabular}{|c|c|c|c|}
\hline Variable & $\begin{array}{l}\text { Case group } \\
\mathrm{n}=45\end{array}$ & $\begin{array}{l}\text { Control group } \\
\mathrm{n}=36\end{array}$ & $\mathrm{p}$-value \\
\hline Age & $62.7 \pm 13$ & $60.1 \pm 11.9$ & 0.380 \\
\hline Male, $\mathrm{n}(\%)$ & $31(68.9 \%)$ & $18(50 \%)$ & 0.080 \\
\hline Current smoker, n (\%) & $11(24.4 \%)$ & $2(5.6 \%)$ & $0.020 *$ \\
\hline HTN, n(\%) & $8(17.8 \%)$ & $11(30.6 \%)$ & 0.180 \\
\hline Type 1 DM, n (\%) & $2(4.4 \%)$ & $4(11.1 \%)$ & 0.400 \\
\hline Type 2 DM, n (\%) & $7(5.6 \%)$ & $4(11.1 \%)$ & 0.560 \\
\hline Total cholesterol $\left(\mathrm{mg} \mathrm{dL}^{-1}\right)$ & $189.2 \pm 43.7$ & $176.3 \pm 32.3$ & 0.140 \\
\hline LDL-C (mg dL $\left.{ }^{-1}\right)$ & $112.8 \pm 35.6$ & $106 \pm 28.7$ & 0.360 \\
\hline HDL-C (mg dL $\left.{ }^{-1}\right)$ & $46.2 \pm 11.4$ & $42.3 \pm 10$ & 0.110 \\
\hline LDL/HDL ratio & 4.23 & 4.24 & 0.960 \\
\hline Triglyceride $\left(\mathrm{mg} \mathrm{dL}^{-1}\right)$ & $146.1 \pm 97.6$ & $153 \pm 105.5$ & 0.760 \\
\hline Cardiotrophin-1 (mg dL $\left.{ }^{-1}\right)$ & $615.279 \pm 5.109$ & $534.767 \pm 6.750$ & $0.001 *$ \\
\hline
\end{tabular}

We examined the association between plasma concentrations of CT-1 and selected cardiovascular risk factors.

There was a significant association between plasma CT-1 level with HTN in the case and the control groups.

But there was not found any significant association between plasma CT-1 level with Type 1 DM, Type 2 DM, age, sex, LDL, HDL, TG, total cholesterol and adjusted smoking.

Also we didn't find a statically significant association of plasma concentrations of CT-1 with type of MI, LV systolic Function (EF) and mortality in the cases and with sex and not with age in all subjects.

There was not significant difference between Plasma concentrations of CT-1 in patients with STEMI and those with NSTEMI $\left(615.038 \pm 0.575 \mathrm{pmol} \mathrm{L}^{-1} \mathrm{Vs}\right.$ 615.647 $\pm 4.443 \mathrm{pmol} \mathrm{L}^{-1},(\mathrm{p}=0.707)$.

\section{DISCUSSION}

In this case-control study, in line with previous studies (Freed et al., 2003; 2005; Khan et al., 2006). We found that high plasma CT-1 levels were associated with AMI among Iranian patients independent of traditional cardiovascular risk factors.

Previous studies have shown that the elevation of CT-1 in human hypertension (Freed et al., 2003. Lopez et al., 2005) and its potential role in post-MI wound healing (Pemberton et al., 2005).

Pemberton et al. (2005) showed that CT-1 Plasma cardiotrophin-1 is elevated in human hypertension and stimulated by ventricular stretch and the same result was shown by Lopez et al. (2005) in hypertensive heart disease.

Previous researches showed the role of inflammation acute coronary syndrome (Trepels et al., 2004; Biasucci et al., 2000).
Gonzalez et al. (2005) showed that evaluation of plasma cardiotrophin-1 concentration is useful in assessment of left ventricular hypertrophy regression in hypertensive patients.

Like our findings, Trepels et al. (2004). Found the role of inflammation in acute coronary syndrome and Schuett et al. (2009) describe the role of IL-6 and its signaling as an inflammatory cytokine in atherosclerosis.

The presence of inflammatory infiltrates in unstable coronary plaques suggests that inflammatory processes may contribute to the pathogenesis of acute coronary syndromes.

The Concentrations of pro-inflammatory cytokines, such as Interleukin (IL) 1 and 6 and of acute phase reactants are increase in patients with unstable angina and myocardial infarction (Biasucci et al., 2000).

As CT-1 is a member of the IL-6 family of cytokines - as an inflammatory cytokine-, our result is supported by previous studies indicating the role of inflammation in atherosclerosis (Trepels et al., 2004; Schuett et al., 2009; Gonzalez et al., 2005).

Although little is known about the role of CT-1 in atherosclerosis it would be possible that CT-1 such as IL-1 and IL-6 (Gonzalez et al., 2005). contributes to destabilize of atherosclerotic plaques.

In this study there was a significant association between plasma CT-1 level with HTN in the case and the control groups. The same results were found in other studies (Freed et al., 2003; Lopez et al., 2005). But there was not found any significant association between plasma CT-1 level with Type 1 DM, Type 2 DM, age, sex, LDL, HDL, TG, total cholesterol and adjusted smoking and also with type of MI, LV systolic Function (EF) and mortality in our cases.

These results suggest that plasma levels of CT-1 are independent of these variables.

There was not significant difference between Plasma concentrations of CT-1 in patients with STEMI and those with NSTEMI $\left(615.038 \pm 5.575 \mathrm{pmol} \mathrm{L}^{-1} \mathrm{Vs}\right.$ $615.647 \pm 4.443$ pmol L $\left.^{-1}, p=0.707\right)$ that shows CT-1 does not affect on ST. But we did not any data indicating association of CT-1 with these parameters to compare the results.

\section{CONCLUSION}

These results show an association between HTN and the plasma concentration of CT-1 in AMI. Although preliminary, these findings suggest that the determination of CT-1 may be an easy and reliable method for the initial screening and diagnosis of AMI. 


\section{ACKNOWLEDGEMENT}

This study was supported by Vice Chancellor for Education and Research of the Jahrom University of Medical Sciences. The authors are grateful to the patients and the control individuals who accepted to enter this study.

\section{REFERENCES}

Ahmed, I.A., 2010. Myocardial-infraction based on intelligent techniques. Am. J. Applied Sci., 7: 349-351. http://www.scipub.org/fulltext/ajas/ajas73349-351.pdf

Azimzade-Sarwar, B., G. Yousefzade and S. Narooey, 2005. A case-control study of effect of opium addiction on myocardial infarction. Am. J. Applied Sci., $\quad 2$ : 1134-1135. http://www.scipub.org/fulltext/ajas/ajas2711341135.pdf

Antman, E.M., M. Hand, P.W. Armstrong, E.R. Bates and L.A. Green et al., 2008. 2007 focused update of the ACC/AHA 2004 guidelines for the management of patients with ST-elevation myocardial infarction: A report of the American College of Cardiology/American Heart Association Task Force on Practice Guidelines: Developed in collaboration With the Canadian Cardiovascular Society endorsed by the American Academy of Family Physicians: 2007 Writing Group to Review New Evidence and Update the ACC/AHA 2004 Guidelines for the Management of Patients With ST-elevation myocardial infarction, writing on behalf of the 2004 writing committee. Circulation, 117: 296-329. PMID: 18071078

Biasucci, L.M., G. Liuzzo, D.J. Angiolillo, G. Sperti and A. Maseri, 2000. Inflammation and acute coronary syndromes. Herz, 25: 108-112. PMID: 10829249

Cannon, C.P., 2010. Strategies and Therapies for Reducing Ischemic and Vascular Events (STRIVE): Updated standing orders for STsegment elevation myocardial infarction and unstable angina/non-ST-segment elevation myocardial infarction. Crit. Pathw. Cardiol., 9: 55-81. PMID: 20520214

Dehlaghi, V., S. Najarian and M.T. Shadpour, 2008. Effect of stent geometry on phase shift between pressure and flow waveforms in stented human coronary artery. Am. J. Applied Sci., 5: 340-346. http://www.scipub.org/fulltext/ajas/ajas54340-346.pdf

Foster, J.J. and W. Pitts, 2009. Implementation of an insulin therapy protocol: Applying the Baldrige approach. Am. J. Health Syst. Pharm., 66: 1035-1038. PMID: 19451615
Freed, D.H., M.C. Moon, A.M. Borowiec, S.C. Jones and P. Zahradka et al., 2003. Cardiotrophin-1: Expression in experimental myocardial infarction and potential role in post-MI wound healing. Mol. Cell Biochem., 254: 247-256. PMID: 14674704

Freed, D.H., R.H. Cunnington, A.L. Dangerfield, J.S. Sutton and I.M. Dixon, 2005. Emerging evidence for the role of cardiotrophin-1 in cardiac repair in the infracted heart. Cardiovasc. Res., 65: 782-792. PMID: 15721858

Gonzalez, A., B. Lopez, D. Martin-Raymondi, E. Lozano and N. Varo et al., 2005. Usefulness of plasma cardiotrophin-1 in assessment of left ventricular hypertrophy regression in hypertensive patients. J. Hypertens., 23: 2297-2304. PMID: 16269972

Jahromi, A.S., M. Shojaie, S. Dana and A. Madani, 2010. Anti-cardiolipin antibody in acute myocardial infarction. Am. J. Immunol., 6: 11-14. http://www.scipub.org/fulltext/aji/aji6111-14.pdf

Khan, S.Q., D. Kelly, P. Quinn, J.E. Davies and L.L. Ng, 2006. Cardiotrophin-1 predicts death or heart failure following acute myocardial infarction. J. Card Fail, 12: 635-640. PMID: 17045183

Lang, R.M., 2009. The value of belonging: ASE delivers a broad spectrum of benefits to a diverse membership. J. Am. Soc. Echocardiogr., 22: A27-A28. PMID: 19883869

Lopez, B., A. Gonzalez, J.J. Lasarte, P. Sarobe and F. Borras et al., 2005. Is plasma cardiotrophin-1 a marker of hypertensive heart disease? J. Hypertens., 23: 625-632. PMID: 15716706

Najafi-Parizi, G. and A. Lori, 2005. Periodontal disease as a risk factor for coronary artery disease. Am. J. Applied $\quad$ Sci., $\quad 2$ : $1526-1528$. http://www.scipub.org/fulltext/ajas/ajas21115261528.pdf

Pemberton, C.J., S.D. Raudsepp, T.G. Yandle, V.A. Cameron and A.M. Richards, 2005. Plasma cardiotrophin-1 is elevated in human hypertension and stimulated by ventricular stretch. Cardiovasc. Res., 68: 109-117. PMID: 15978561

Pourahmad, M., A.S. Jahromy and M. Shojaei, 2009. Association of Mycoplasma pneumoniae infection with myocardial infarction. Am. J. Immunol., 5: 84-88. http://www.scipub.org/fulltext/aji/aji5384-88.pdf

Schuett, H., M. Luchtefeld, C. Grothusen, K. Grote and B. Schieffer, 2009. How much is too much? Interleukin-6 and its signaling in atherosclerosis. Thromb. Haemost., 102: 215-222. PMID: 19652871

Shojaie, M., A. Sotoodah and G. Shafaie, 2009a. Is adiponectin associated with acute myocardial infarction in Iranian non obese patients? Lipids Health Dis., 8: 17-17. PMID: 19476644 
Shojaie, M., A. Sotoodah, S. Roozmeh, E. Kholoosi and S. Dana, 2009b. Annexin V and anti-Annexin V antibodies: Two interesting aspects in acute myocardial infarction. Thromb. J., 7: 13-13. PMID: 19622170

Trepels, T., A.M. Zeiher and S. Fichtlscherer, 2004. Acute coronary syndrome and inflammation. biomarkers for diagnostics and risk stratification. Herz, 29: 769-776. PMID: 15599673

Victor, R.G. and N.M. Kaplan, 2008. Systemic Hypertension: Mechanisms and Diagnosis. In: Braunwald's Heart Disease: A Textbook of Cardiovascular Medicine, Libby, P., R.O. Bonow, D.L. Maan and D.P. Zipes (Eds.). Saunders, Philadelphia, pp: 1915-1921.
Zimmerman, F.H., A. Cameron, L.D. Fisher and G. Ng, 1995. Myocardial infarction in young adults: Angiographic characterization, risk factors and prognosis (coronary artery surgery study registry). J. Am. Coll. Cardiol., 26: 654-661. PMID: 7642855 